\title{
Rapid spectroscopic measurement of methanol in water-ethanol- methanol mixtures
}

\author{
Hana Vašková* and Martin Tomeček \\ Tomas Bata University in Zlin, Faculty of Applied informatics, Department of Electronic and Measurements, 76005 Zlin, \\ Czech Republic
}

\begin{abstract}
The paper is focused on the Raman spectroscopic analysis of methanol content in water-ethanolmethanol mixtures as this kind of mixture chemically closely relates to alcoholic drinks. Counterfeit alcoholic drinks represent losses to the economy, but especially can cause serious health risks starting from nausea, to blindness, and even death. Extensive methanol poisonings were reported in last decades in number of countries worldwide. A set of water-ethanol-methanol mixtures with a range of concentrations of methanol from $0 \%$ to $100 \%$ was prepared to obtain the calibration dataset, needful for quantitative assessment. Based on calibration data, test samples and alcoholic beverages were evaluated. Raman spectroscopy is used especially because of this method's benefits as specific vibrational fingerprint, direct measurement through the bottles, no need of additional chemicals and fast response. The study confirms the rapid and accurate analysis complying with safety limits set by methanol spirits legislation.
\end{abstract}

\section{Introduction}

Methanol is the simplest aliphatic alcohol with similar properties to ethanol that cannot be uniquely recognized only by taste or smell. Methanol, itself, has a relatively low inherent toxicity, however, converts in organism into highly toxic compounds with neurotoxic actions on the human retina, can cause blindness, coma and even death $[1,2]$.

In today's world we encounter issues of commodity counterfeiting in various areas, including alcoholic beverages. Those containing higher than safe amounts of methanol then cause poisoning with varying degrees of damage. Extensive health problems and fatalities were reported in number of countries around the world during the last several decades. The last known incident happened in December 2016 in Russia's Irkutsk, 73 people died [3].

Alcohol has become one of the most widely used recreational drugs over the years. Alcohol consumption is characterized by a wide range of behavioural effects and pathological consequences. Ethanol affects the central nervous system and has cushioning effects in general. The effects can be summed up: from feelings of relaxation, happiness, euphoric emotions activation after low dose consumption $[4,5]$, over a reaction speed reduction, perception and/or memory reduction, loss of coordination, intellectual impairment, impulsive behavior, aggression, sleep disruption after moderate dose $[6,7]$, to clinical depression, poisoning, a narcotic effect and at worst death after consumption of large dose of alcohol [5].
Searching for innovative detection methods of alcoholic beverages illegally enriched with methanol (or other toxic substances) with advantageous requirements to simplify measurement process, but to ensure adequate reporting value is desirable and one of the alternative option is discussed in this paper.

\section{Motivations}

The motivation for the study of methanol detection is based on two main points. The first concerns the methanol poisonings, which broke out in the Czech Republic in September 2012, 127 people were poisoned, 42 died. Majority, but not all of adulterated liquor was confiscated. The second concerns the already studied potential of Raman spectroscopy for various kinds of material analysis [8,9]. The crucial benefits for methanol (and alcoholic beverages) analysis are: rapidity of measurement (seconds), specific vibrational fingerprint, direct measurement through covering materials (i.e. glass bottles), no additional chemicals.

\subsection{Official methods}

Official laboratory analysis of methanol content in solutions (alcoholic drinks) is performed by chromotropic acid colorimetric method (recommended as official methods by International Organization for Standardization and Association of Official Analytical Chemists [10]. Chromatographic methods GC-MS, GCFID, HPLC or spectroscopic FT-IR is also used [11].

* Corresponding author: vaskova@,fai.utb.cz 


\subsection{Why Raman spectroscopy?}

Raman spectroscopy is an effective vibrational spectroscopic method with a potential to answer a number of questions related to chemical details on molecular level. This fundamental fact makes this technique suitable for material identification [12]. Raman spectroscopy seems to be a very promising analytical tool in recent years in number of scientific areas such as biochemistry, material science, food science; for forensic and security purposes [13].

Raman spectroscopy brings many benefits as the method is relatively rapid, non-destructive, contactless, highly sensitive, usable for measuring through transparent glass or polymeric covering layers and containers, applicable to all states of matter and different forms, without special requirements for sample preparation, usable as in situ analysis.

Although the fundamental phenomenon is known since thirties of the 20th century, its effective utilization in various scientific areas has progressed over the about last decade. The trend in device minimization allows field use with portable spectrometers.

\section{Experimental part}

\subsection{Materials and Samples}

The three liquids were used for the preparation of the samples: min. $99.5 \%$ concentrated methanol (batch: 278701), min. 99.5\% absolute anhydrous ethanol (batch: 48401), distilled water.

Twelve mixtures of ethanol, methanol and distilled water were prepared as a calibration dataset, all of the total volume $4 \mathrm{ml}$. Resulting alcohol content in all samples was $40 \%$ by volume. The quantities of methanol concentrations were set at $0 \%, 0.1 \%, 0.25 \%$, $0.5 \%, 0.75 \%, 1 \%, 3 \%, 5 \%, 10 \%, 20 \%, 50 \%$ and $100 \%$ for the individual samples, quantities of ethanol were calculated. Determined amounts of methanol and ethanol were pipetted into glass cuvettes, distilled water was added and cuvettes immediately fitted with a closure to avoid evaporation of the solution. Raman spectroscopy offers the benefit of measuring through transparent packaging materials, such as glass or polymers, which is in the case of volatile, flammable and toxic substances highly competitive.

Test mixtures were prepared similarly to calibration samples. The quantities of methanol concentrations were set at $0.6 \%, 0.9 \%, 1.5 \%, 3.5 \%$ and $14.5 \%$.

\subsection{Instrumentation}

InVia Basis Raman microscope by Renishaw was performed for measuring all samples. The Raman microscope uses two lasers as light sources: argon ion laser with the excitation wavelength $514 \mathrm{~nm}$ and maximum output power $20 \mathrm{~mW}$; and $785 \mathrm{~nm}$ NIR diode laser with maximum output power $300 \mathrm{~mW}$. Both were tested. More precise data were obtained using NIR laser.
A Leica DM 2500 confocal microscope with the resolution $2 \mu \mathrm{m}$ was coupled to the Raman spectrometer. The total magnification was $50 \mathrm{x}$.

All measurements were collected with $5 \mathrm{~s}$ exposure time and 10 accumulations. The samples were firstly scanned in the range 100 to $3200 \mathrm{~cm}^{-1}$ with $2 \mathrm{~cm}^{-1}$ spectral resolution. After determining the principle vibrational response, attention was focused on two specific domains: $500 \mathrm{~cm}^{-1}-1300 \mathrm{~cm}^{-1}$ and $2600 \mathrm{~cm}^{-1}-$ $3200 \mathrm{~cm}^{-1}$.

\subsection{Measured data and Results}

\subsubsection{Liquid mixtures in glass cuvettes}

Due to the measurement of liquid mixtures in glass cuvettes, it was firstly necessary to ascertain the influence of the packaging material - glass. A dominant band centred on $1368 \mathrm{~cm}^{-1}$ can be seen in Fig.1. The depth scanning was performed to find the thickness of the glass wall of the cuvette for the right depth of focus of the laser beam and as information about glass signal influence in spectra. The depth scanning showed that the proper depth for the measurement of the liquids is $2.5 \mathrm{~mm}$. The broad band of the glass is still visible, however, much lower in comparison to the signal of the alcohol as is demonstrated in Fig. 1.

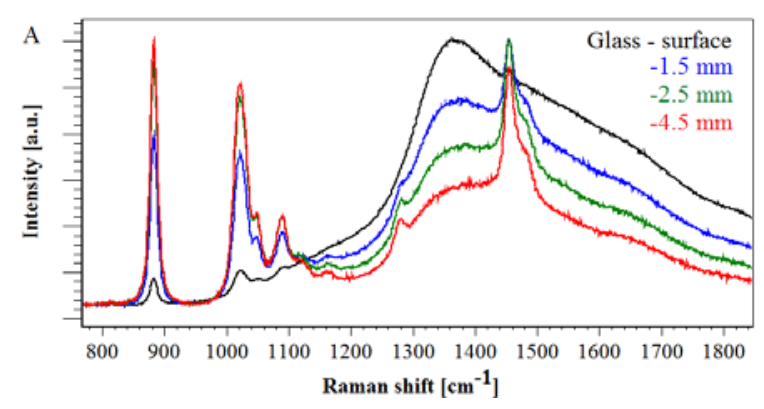

Fig. 1 Raman spectra of depth scan from the surface of glass cuvette into sample inside.

\subsubsection{Pure alcohol}

The pure methanol and ethanol were measured and the principal Raman bands were identified. Obtained Raman spectra are displayed in Fig. 2. The assignments are listed in Table 1 and Table 2.

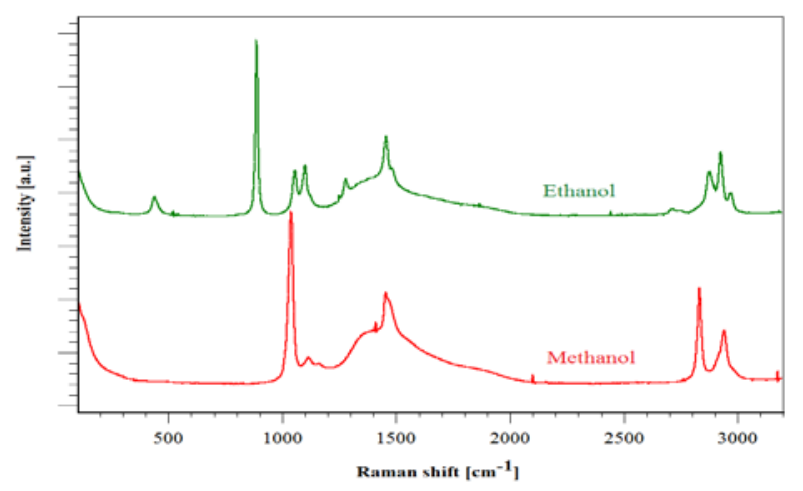

Fig. 2 Raman spectra of pure ethanol and methanol. 
Table 1. Assignment of Raman bands of methanol.

\begin{tabular}{|c|c|c|}
\hline $\begin{array}{c}\text { Measured } \\
\text { data }\end{array}$ & $\begin{array}{c}\text { Data from } \\
\text { literature [14, 15] }\end{array}$ & Assignment \\
\hline 1036 & 1033 & C-O Stretching \\
\hline 1113 & 1106 & $\mathrm{CH}_{3}$ Rocking \\
\hline 1160 & 1149 & $\mathrm{CH}_{3}$ Bending \\
\hline 1452 & 1448 & $\mathrm{CH}_{3}$ Bending \\
\hline 2837 & 2832 & $\begin{array}{c}\mathrm{C}-\mathrm{H} \text { Symetric } \\
\text { Stretchning }\end{array}$ \\
\hline 2946 & 2940 & $\begin{array}{c}\mathrm{C}-\mathrm{H} \text { Antisymetric } \\
\text { Stretching }\end{array}$ \\
\hline
\end{tabular}

Table 2. Assignment of Raman bands of methanol.

\begin{tabular}{|c|c|c|}
\hline $\begin{array}{c}\text { Measured } \\
\text { data }\end{array}$ & $\begin{array}{c}\text { Data form } \\
\text { literature }[14,15]\end{array}$ & Assignment \\
\hline 885 & 883 & C-C Stretching \\
\hline 1053 & 1054 & C-O Stretching \\
\hline 1098 & 1096 & $\mathrm{CH}_{3}$ Rocking \\
\hline 1277 & 1454 & $\mathrm{CH}_{3}$ Bending \\
\hline 1455 & 1479 & $\mathrm{CH}_{3}$ Bending \\
\hline 2881 & 2878 & $\begin{array}{l}\mathrm{CH}_{2}-\mathrm{CH}_{3} \\
\mathrm{Stretching}\end{array}$ \\
\hline 2931 & 2929 & $\begin{array}{l}\mathrm{CH}_{2}-\mathrm{CH}_{3} \\
\mathrm{Stretching}\end{array}$ \\
\hline 2976 & 2972 & $\begin{array}{l}\mathrm{CH}_{2}-\mathrm{CH}_{3} \\
\mathrm{Stretching}\end{array}$ \\
\hline
\end{tabular}

\subsubsection{Alcohol-water solutions}

The methanol-water and ethanol-water mixtures were measured. Several wavenumber shifts have been observed in both of the measured domains. A red shift in the first domain $1000 \mathrm{~cm}^{-1}-1100 \mathrm{~cm}^{-1}$ : the band 1036 $\mathrm{cm}^{-1}$ corresponding to $\mathrm{C}-\mathrm{O}$ stretching of methanol was shifted to $1022 \mathrm{~cm}^{-1}$. A blue shift in the second domain $2800 \mathrm{~cm}^{-1}-3000 \mathrm{~cm}^{-1}$ : the band $2837 \mathrm{~cm}^{-1}$ corresponding to $\mathrm{C}-\mathrm{H}$ symmetric stretching was shifted to $2845 \mathrm{~cm}^{-1}$ and $2946 \mathrm{~cm}^{-1}$ corresponding to $\mathrm{C}-\mathrm{H}$ antisymmetric stretching of methanol was shifted to $2953 \mathrm{~cm}^{-1}$. Described shifts are shown in Fig. 3 and Fig. 4. Both types of shifts are related to a structure of aqueous alcohol solutions at the molecular level and for several different concentrations are mentioned in literature [16, 17]. The details of their molecular structuring has not been explained yet, however, it is believed to be caused by the arresting thermodynamic properties of aqueous alcohol solutions that are the subject of many studies, the differences in energy of hydrogen bonding between water-water, alcohol-alcohol, and alcohol-water molecules [17].

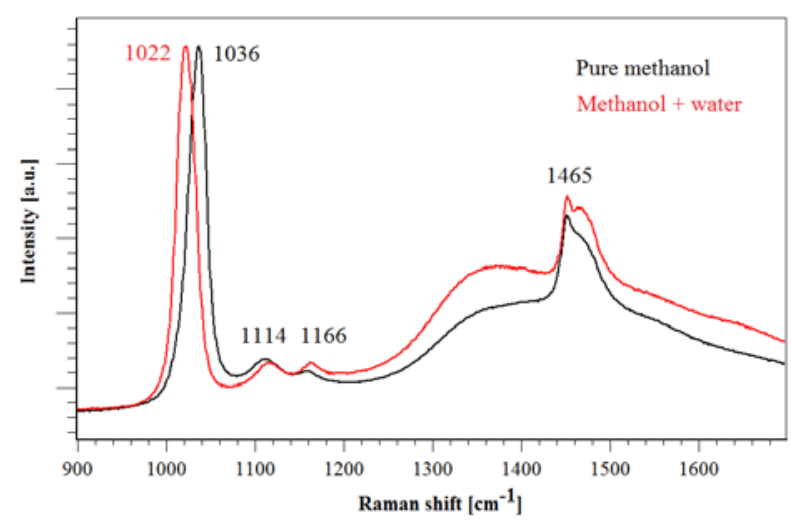

Fig. 3 Red shift of the $1036 \mathrm{~cm}^{-1}$ band of methanol in methanol-water solution.

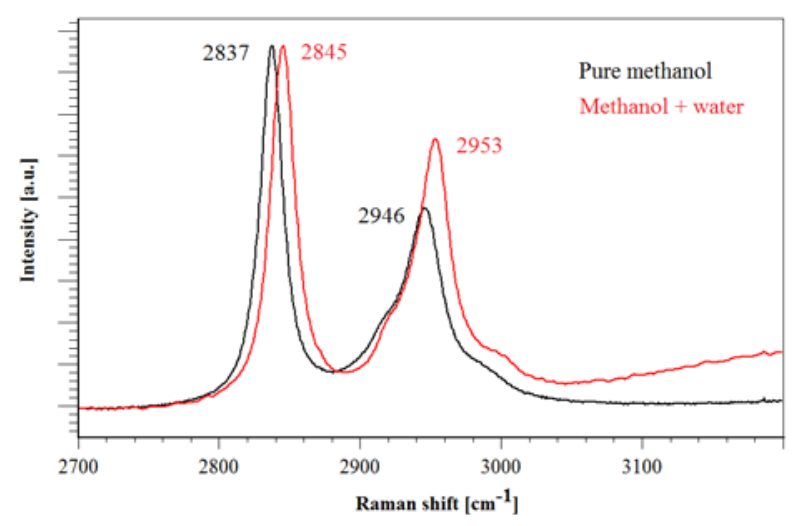

Fig. 4 Blue shift of the $2837 \mathrm{~cm}^{-1}$ and $2946 \mathrm{~cm}^{-1}$ bands of methanol in methanol-water solution.

\subsubsection{Calibration}

The next step was the measurement of the calibration dataset. Two bands were used for the analysis: $1036 \mathrm{~cm}^{-1}$

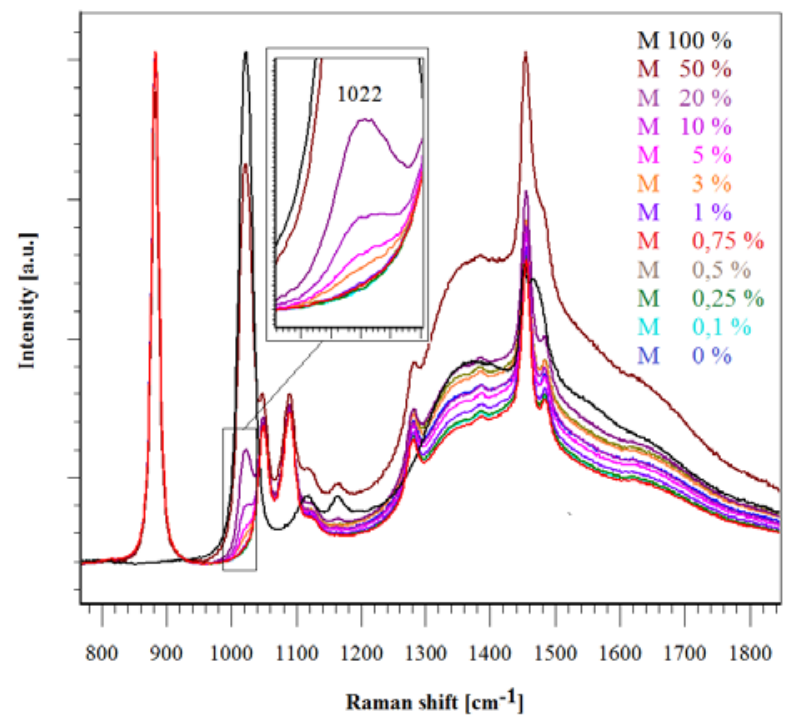

Fig. 5 Raman spectra of calibration dataset. 


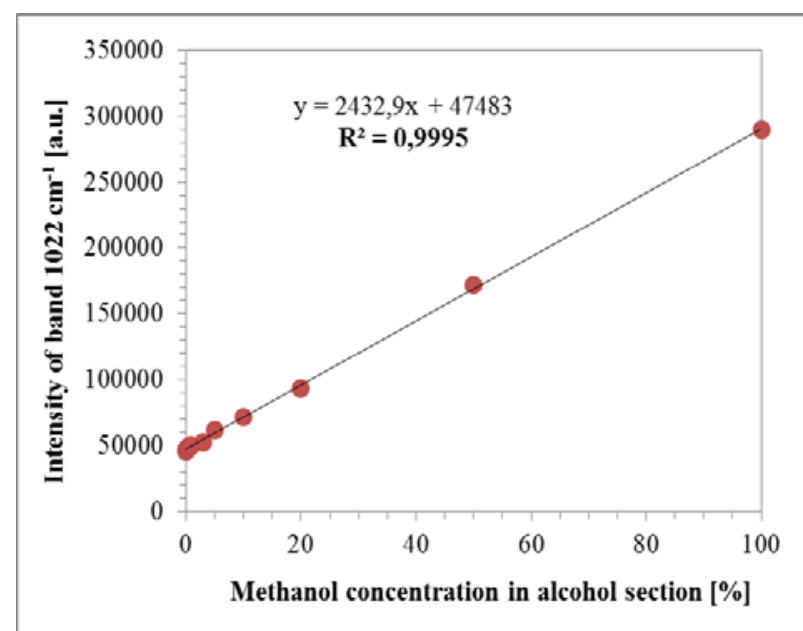

Fig. 6 Calibration curve for methanol content in ethanolmethanol-water solution based on intensity of $1022 \mathrm{~cm}^{-1}$ band.

(C-O stretching) for methanol, and $885 \mathrm{~cm}^{-1}$ (C-C stretching) for ethanol. These bands were chosen because of their strong intensity and separated position in the spectra. A baseline correction with the cubic spline interpolation with a defined identical Raman shift positions was applied to all the data. Raman spectra of the calibration dataset are displayed in Fig. 5. Two calibration curves were obtained, one based on intensities of $1022 \mathrm{~cm}^{-1}$ band (Fig. 6), the second based on $1022 \mathrm{~cm}^{-1}$ band areas. The intensities respectively band areas were subjected to the least square regression resulting in a linear dependence with coefficient of determination 0.9995 respectively 0.9980 . The obtained data confirm the possibility to measure below the value of allowed concentration limit of methanol in distillates (after calculation corresponds to the smaple with the concentration $0.75 \%$ ). This limit is in the Czech Republic governed by Regulation (EC) No 1334/2008 of the European Parliament and of the Council.

\subsubsection{Verification}

The process of methanol determination was verified on test samples, which were measured and data processed in the same manner as the calibration set. Using the calibration model for evaluation, the results indicated more precise evaluation using intensity of $1022 \mathrm{~cm}^{-1}$ Raman band compared to the $1022 \mathrm{~cm}^{-1}$ band areas. The measure of precision was 0.03 in average.

\subsubsection{Alcoholic beverages}

Alcoholic beverages are, in fact, mixtures of ethanol, water and (eventually) low concentration of methanol plus essences arising from the origin ingredients for the fermentation. Samples of plum brandy (40\% alc./vol.), vodka (40\% alc./vol.) and whisky (40\% alc./vol.) were analysed. Methanol content in all tested drinks was under the allowed (safe) limit with the exception of one plum brandy sample, which exceed the allowed limit.

\section{Conclusions}

Alcoholic drinks are consumed worldwide. The content of methanol exceeds the allowed limit from time to time, accidently or intentionally. The results of the study show, that Raman spectroscopy is an appropriate method for methanol content analysis in water-ethanol-methanol mixtures and alcoholic drinks, for qualitative and quantitative analyses. Quantitative assessment requires precise calibration data. Raman spectroscopy brings benefits of rapidity, measurements through glass (or polymer) cover, no need for additional chemical and no preparation. Therefore, the requirements for immediate, simple and accurate detection of alcohol safety are met.

This work was supported by the Ministry of Education, Youth and Sports of the Czech Republic within the National Sustainability Programme project No. LO1303 (MSMT7778/2014) and also by the European Regional Development Fund under the project CEBIA-Tech No. CZ.1.05/2.1.00/03.0089.

\section{References}

1. J.L. Treichel, M.M. Henry, C.M., Skumatz, J.T. Eells, J.M. Burke, Neurotoxicology 24, 6 (2003)

2. D.G. Barceloux et al, J Toxicol Clin Toxicol 40, 4 (2002)

3. V. Smirnov. Sputnik News Agency [online] $(01 / 2017)$

4. M. Kano et al, Hum Psychopharmacol 18, 2 (2003)

5. C. Baum-Baicker, C. Drug Alcohol Depend 15, 4 (1985)

6. J. Zikmund, Toxicology [online] (2006)

7. M.M. Thakkar et al., R. Sharma, P. Sahota, Alcohol 49, 4 (2015)

8. H. Vaskova, MATEC Web Conf. (2016)

9. H. Vaskova, M. Buckova, MATEC Web Conf. (2017)

10. Official Methods of Analysis of AOAC International, (1990)

11. B.J. Savary, A.Nuñez, J Chromatogr A 1017 (2003).

12. J.M. Chalmers, G.E. Howell, M.D. Hargreaves. Infrared and Raman spectroscopy in forensic science (Wiley, 2012)

13. G.S. Bumbrah, R.M. Sharma, Egypt J Forensic Sci, 6, 3 (2016)

14. A. Picard et al. Extremophiles 11, 3 (2007)

15. J.F. Mammone, S.K. Sharma, M. Nicol. J Phys Chem 84, 23 (1980)

16. B. Wu, Y, Liu, J. Lu, Spectrosc Spect Anal 31, 10 (2011)

17. T.A. Dolenko, S.A. Burikov, S.A. Dolenko, A.O. Efitorov, I.V. Plastinin, V.I. Yuzhakov, S.V. Patsaeva. J Phys Chem A 119, 44 (2015) 